\title{
What motivates higher education educators to innovate? Exploring competence, autonomy, and relatedness - and connections with wellbeing
}

\section{Robin Margaret Averill \& Jae Major}

To cite this article: Robin Margaret Averill \& Jae Major (2020): What motivates higher education educators to innovate? Exploring competence, autonomy, and relatedness - and connections with wellbeing, Educational Research, DOI: 10.1080/00131881.2020.1755877

To link to this article: https://doi.org/10.1080/00131881.2020.1755877

曲 Published online: 23 Apr 2020.

Submit your article to this journal $₫$

View related articles $Ґ$

View Crossmark data $₫$ 


\title{
What motivates higher education educators to innovate? Exploring competence, autonomy, and relatedness - and connections with wellbeing
}

\author{
Robin Margaret Averill (D) and Jae Major (D) \\ School of Education, Victoria University of Wellington, Te Herenga Waka, Kelburn, New Zealand
}

\begin{abstract}
Background: High quality tertiary teaching is important for maximising the impact of tertiary education for students, employers and society, as well as for institutional reputation and accountability. Varied interpretations exist regarding what counts as 'innovative' tertiary teaching.
\end{abstract}

Purpose: This study sought to explore the deeper drivers of motivations of tertiary educators to initiate and implement teaching innovations.

Method: Drawing from the data from semi-structured interviews from a wider study into innovative teaching in a tertiary education institution in Aotearoa New Zealand, we analysed the rationale of 13 expert tertiary educators for teaching in novel ways. The framework for analysis was based on Self-Determination Theory: data were analysed in relation to three basic psychological needs known to impact on motivation and wellbeing - competence, autonomy and relatedness.

Findings: Our analysis suggests that tertiary educator motivation to innovate in their teaching is related to feelings of all three needs. Findings suggest that innovative pedagogical change was linked to educators' need for feelings of competence in relation to subject area content, pedagogy and developing student competence. Enhancing autonomy for the educators themselves, or for their students, was also an important factor motivating innovative practice. Developing relatedness between students, between themselves and students, and between students and society were reported as motivations for innovative teaching. Some teaching innovations were motivated by the educator's desire for greater personal or student wellbeing.

Conclusions Educators' motivations for being innovative in their tertiary pedagogical practice encompassed content, pedagogical, personal and social dimensions. None reported that their innovation was motivated by institutional policy or expectations. The reported challenges to innovative teaching practice, including institutional structures and processes, lack of access to specific technologies, and the time needed to develop and implement changed practice, indicate that educators must be strongly committed to making change in their practice to sustain the effort required.

\section{ARTICLE HISTORY}

Received 17 December 2019

Accepted 11 April 2020

\section{KEYWORDS}

Innovative teaching; higher education; motivation; wellbeing; Self-

Determination Theory; student engagement 


\section{Introduction}

The role and quality of teaching in higher education have become key focus areas for universities internationally in recent years (Henard and Roseveare 2012). There are many institution-driven and student-related reasons for the increased attention on tertiary level teaching and pedagogical innovation. For example, student demographics have changed with increasing numbers now studying at university and greater diversity in the student population in terms of culture and language, ethnicity, socio-economic status and age (Henard and Roseveare 2012; Layne and Lake 2014). In addition to demographic changes, the skills and understandings needed by graduates for living and working in the twenty-first century are also changing. There is an increasing emphasis on employability and 'real world' skills in higher education (Furco and Moely 2012; Kettunen, Kairisto-Mertanen, and Penttilä 2013), with associated changes in approaches to teaching and learning needed. Students increasingly expect to be taught in ways that are engaging and authentic, and that prepare them adequately for future employment (Kennedy et al. 2009; Seely Brown and Adler 2008).

Rapid technological advances that demand digital fluency from students and educators (Adams Becker et al. 2017) further challenge traditional approaches to tertiary teaching. Many students in higher education have experienced much of their world via digital technologies (McCurry and Martins 2010). However, there are tensions between the open, 'anytime, anywhere' potential of digital devices and 'the control culture of education' (McLoughlin and Lee 2010, 31), so, while universities may use virtual learning environments and online learning management systems, pedagogical practices have often remained largely traditional.

The widespread development of teaching awards, tertiary teaching qualifications and tertiary professional development programmes show efforts are in place in many contexts towards enhancing motivation, incentives and opportunities for educators to incorporate innovative approaches into their teaching practice. Given that pedagogical change is called for to ensure tertiary teaching is able to meet the academic and affective needs of current and future students in tertiary education, there is a pressing need for higher education institutions to understand educator motivation to innovate (or not) in their pedagogical approaches. The research reported here draws on data from a wider study of innovative approaches to teaching and learning at one New Zealand university. In this article, we focus on two questions:

- What are the personal motivations to initiate and implement teaching innovations of expert tertiary educators?

- How do motivations for tertiary teaching innovation relate to educator and student wellbeing?

We first outline themes from the empirical literature relating to innovative pedagogies in the context of higher education. We then introduce Self-Determination Theory (SDT) (Deci and Ryan 2017; Ryan and Deci 2000) and related notions of wellbeing, and explain the research design. We examine expert tertiary educators' explanations about their practice using the dimensions of the three basic psychological needs from SDT, and argue that feelings of all three are essential for educators' motivation to innovate in their tertiary teaching. Finally, we discuss how using notions from SDT as an underpinning framework can contribute to understanding and supporting pedagogical innovations in higher education. 


\section{Innovative approaches to teaching in higher education}

Defining innovative pedagogies is a recurrent challenge in much of the literature. For the purposes of this article, pedagogical innovations are taken to be planned and intentional; new, in the sense of being 'a departure from what has been done before' (Hannan, English, and Silver 1999, 280), and intended to improve student learning and achievement (Law 2014; Stupans, Scutter, and Pearce 2010; Walder 2014). There is much literature that reports on innovations introduced in tertiary teaching (e.g. McLoughlin and Lee 2010; Stupans, Scutter, and Pearce 2010), and a wide variety of teaching innovations have been reported on. However, there are few studies that focus on educators' motivations to innovate. One early study is Hannan, English, and Silver (1999), who interviewed over 200 academics across England to identify the motivations which drove innovations in teaching, learning and assessment in higher education. They found that a key reported motivation for innovation was to improve student learning, which encompassed motivating students, preparing them for employment, finding better ways to teach and giving students more responsibility for their learning. Lock et al. $(2018,4)$ found that educators' innovations often start with a 'vision for teaching and learning and ... dissatisfaction with current practice'. Other motivations for innovation relate to factors beyond the lecturers' control, such as addressing demands of external agencies, curriculum change, changes in student intake or internal reorganisation (Hannan, English, and Silver 1999).

Student engagement is the most often cited reason for interest in and uptake of innovative approaches by academics, and much recent research has focused on using new technologies to enhance student engagement. For example, in a study that investigated the motivations of lecturers in a South African university to use emerging technologies, Backhouse (2013) found that innovations were mainly motivated by pedagogical concerns and pragmatism, with teaching and learning enhanced through exploitation of affordances of technology. In addition, a sense of fun and novelty motivate some academics to introduce innovative approaches, to maintain student interest as well as their own enjoyment of teaching (e.g. Stupans, Scutter, and Pearce 2010). Other factors that influence academics' motivation and willingness to engage with innovative practice include whether or not suitable infrastructure and technology support are available, whether there are opportunities for professional development, career progression, an institution-based reward, or to gain expertise without undue time commitment (Furco and Moely 2012; Porter and Graham 2016; Smith 2011). Fear of failure, lack of knowledge about innovative practice and high teaching loads are identified constraints that impact negatively on the development of innovative practice (Porter and Graham 2016; Schell 2006).

The research described above identifies mainly extrinsic motivations as to why educators innovate their teaching. It focuses on describing rather than theorising motivations for pedagogical innovation. As we were interested in exploring the deeper internal drivers for innovation, we employed concepts from SDT to help us examine how motivation to innovate teaching can be explained by basic psychological needs.

\section{Conceptual background}

SDT (Deci and Ryan 2017; Ryan and Deci 2000) helps us understand and explain human motivation, development and psychological health and wellbeing, and can assist in 
predicting performance outcomes. Both 'autonomous motivation' (related in the main to intrinsic motivation and volition) and 'controlled motivation' (associated with external regulation, reward, or punishment) can positively impact action. Autonomous motivation, at conscious and non-conscious levels, is known to have stronger beneficial effects than controlled motivation on psychological health, performance and persistence (Deci and Ryan 2008, 2017; Ryan and Deci 2000). SDT identifies 'competence', 'autonomy' and 'relatedness' as basic, universal inter-connected psychological needs that, together, affect both types of motivation. The degree to which these needs are met enhances or diminishes functioning, self-motivation and psychological health and wellbeing, with strong feelings of satisfaction related to all three being most beneficial for developing strong autonomous orientation to tasks. These concepts of SDT are helpful for examining academics' motivations to innovate their teaching, and conditions that can enhance or limit their feelings of autonomy, competence and social connectedness, in relation to their teaching.

The psychological need for competence refers to feelings of self-efficacy: that is to say, believing in one's ability to function successfully and efficiently within the social environment. In order to innovate, we suggest that tertiary educators need to feel competent in relation to both course content and pedagogy. Competence encompasses the experience of 'opportunities and supports for the exercise, expansion and expression of one's capacities and talents' (Deci and Ryan 2017, 86). Feedback both positively and negatively affects feelings of competence, mediated by one's perceived competence. Feelings of competence can positively affect intrinsic motivation, particularly when accompanied by a sense of autonomy (Ryan and Deci 2000). Tertiary educators with a strong sense of competence will have the confidence to initiate teaching innovations.

A sense of autonomy describes one's perceived internal locus of causality (de Charmes 1968), the belief that, as individuals, we can make our own decisions about things that affect us. Autonomy 'refers not to being independent, detached, or selfish but rather to the feeling of volition that can accompany any act, whether dependent or independent, collectivist or individualist' (Ryan and Deci 2000, 74). Autonomy is most strongly felt by educators when they are free to make pedagogical decisions, rather than experiencing such decisions as being controlled externally. In order to support autonomy, institutional structures such as course information, teaching and assessment requirements should reflect and support academics' choices and freedom to make teaching decisions about innovative practice. Autonomy is also a significant motivator for students. Student experiences of autonomy-fostering tertiary teaching have been found to be enhance students' own curiosity, thirst for challenge, intrinsic motivation, and development of innovation (Martín, Potočnik, and Fras 2017; Ryan and Deci 2000), and 'autonomous actions more fully engage individuals' talents, abilities and energies' (Deci and Ryan 2017, 98).

Relatedness describes the need to belong and to be connected with others; to feel respected, responded to and important to others (Deci and Ryan 2107; Ryan and Deci 2000). Relatedness can be enhanced by establishing mutual care and support through interactions with others. Strong relatedness in tertiary education contexts extends beyond the scope of a traditional educator-student relationship, enabling teaching to be more closely linked to the educator's and students' personal backgrounds, experiences, priorities and prior knowledge. Such teaching draws on emotional as well as cognitive responses, with community building and a sense of community being typical results. 
These three basic needs are inter-related and, when all three are satisfied, wellbeing is enhanced. A small number of studies has investigated educator and student wellbeing using SDT. According to Hobson and Maxwell (2017), the wellbeing of educators impacts their teaching effectiveness, which, in turn, impacts the wellbeing of their students. In a study of early career secondary teachers using SDT, they found that relatedness, which manifested through relationships with students, was the single biggest factor impacting wellbeing. Similarly, Aldrup et al. (2017) found that feelings of competence and relatedness correlated highly with enthusiasm and wellbeing amongst beginning teachers.

\section{Purpose}

This study was a strategic initiative to investigate the innovative pedagogical approaches and practices amongst academics in one university, with the goal of determining how best to support and facilitate pedagogical innovations likely to contribute to student engagement and learning. Our focus was on pedagogical practices that were planned, intentional, different from previous practice, and intended to improve learning and engagement. In this study, we aimed to explore the drivers of motivations of tertiary educators to initiate and implement teaching innovations. We were also interested in investigating the implications of such innovation for the wellbeing of students and educators.

\section{Method}

The methodology of narrative case study (Merriam 2002) was chosen for the wider research from which this article is drawn, to enable exploration of the phenomenon of innovative teaching within the complex naturalistic context of university teaching. To construct case studies of innovative practice to share across the institution, the wider study design was qualitative and included semi-structured interviews of selected academics, online surveys for educators and students, teaching artefacts (e.g. online lectures, assignment descriptions, online teaching sites), student work (e.g. assignments) and focus group interviews with students. The data from interviews with academics have been used for this article.

\section{Ethical considerations}

Approval to conduct this study was sought and granted by the university's Human Ethics Committee. Informed consent was gained from the selected case study participants and focus group students, and all were assured of confidentiality. We were unable to guarantee anonymity for the academic participants because of the small sample size. All these participants were happy to be identified in the case studies about their practice that were posted online (see details below). Confidentiality in this article has been maintained by not identifying the source of data extracts, either by name (or pseudonym), discipline or faculty, or by data source - case study interview or online survey. Focus groups by their nature do not allow for anonymity, but all students who participated signed a consent form that included an agreement to maintain confidentiality of focus group discussions. The data from the online surveys were completely anonymous. Staff and student participants were provided with information before beginning the survey, and informed that the act of completing the survey was considered as consent. 


\section{Setting and participants}

The university setting of the study is fairly typical of many in relation to the focus on and encouragement for academics to develop their teaching. For example, a dedicated team provide support for academic teaching and technical development, lead specific in-house formal qualifications and informal courses. All faculties have learning and teaching committees and other pan-university teaching development groups meet regularly to develop and inform their own and others' teaching. Expert educators have been the focus of previous research (e.g. Gan Joo Seng and Geertsema 2018) and we also sought to draw from such expert educators from our own institution. We purposively selected academics to participate in the study who were identified by at least two of the following criteria; recommended by senior leaders in teaching and learning, recipients of university or national teaching awards, and nominated in the annual institution-based student survey of best teaching practice. Consideration was given to ensuring representation from different faculties and disciplines, undergraduate and postgraduate teaching, campusbased and online teaching, and gender diversity. Six of the 13 resulting participants had used university-based opportunities to develop their teaching or the innovation.

\section{Data collection}

The 13 participants were interviewed as follows. Nine individual interviews were completed and a further two interviews were carried out with colleague pairs, in response to participant request because they worked collaboratively in their teaching innovations. The interviews were digitally recorded and transcribed. Interview questions focussed on the nature and perceived effects for learners of what participants believed to be innovative in their teaching, and their perceptions of the supports for and challenges to their development of these innovative teaching practices. Freedom was given to participants to expand on these areas, with interviewer prompts used to probe for further detail.

\section{Data analysis}

Initial analysis of the data was carried out by the authors independently reading and rereading the interview transcripts, noting instances related to competence, autonomy and relatedness for teaching innovations. The three psychological needs from SDT guided our discussion and description of participants' conscious and non-conscious motivations for developing and implementing pedagogical innovations. Examples of conscious motivation included discussion in which the educator identified both a change in practice and the reason for the change. Non-conscious motivation was inferred from educators' explanations of their priorities and beliefs, without them linking these directly with a specific change or practice. Classification decisions were made together, including when judgement calls had to be made between categories.

\section{Findings and discussion}

The findings from the analysis of participants' responses are discussed below, in relation to their teaching and their intentions for students, where relevant, anonymised quotations 
from the transcribed data are included. The presentation of findings is organised by the framework that underpinned our analysis: i.e. the three needs (competence, autonomy and relatedness); we also discuss the notion of wellbeing as an outcome.

\section{The need for competence}

Three subthemes relating to lecturers' feelings of competence were apparent in the interview data: competence in relation to subject area content, to pedagogy, and to developing student competence. There was strong evidence that educators' feelings of competence motivated innovations in their teaching, and reciprocally, their innovations also contributed to their sense of competence. The detail and enthusiasm apparent in many responses highlighted the value of subject content and the feelings of competence these expert educators had about the content they taught. Examples include comments such as: 'getting [students] excited about engineering and the topics around computer science', 'the applied bit [of the course] is very important to me', and:

I chose that course [for the innovation] because I feel quite personally passionate about maps and I love orienteering, and so the opportunity to do something with maps that actually felt relevant and meaningful for our Māori students was just super exciting for me.

In many ways, competence with content was often invisible, because it was effectively taken for granted as part of academics' practice. However, it was evident in how each educator talked about his/her work. For several educators, concern about students receiving suitable teaching about subject content from tutorial staff motivated their innovations in teaching approaches. For example, in one course, a flipped approach was taken to lectures (i.e. lecture content was turned into short video clips that students could access online) to enable academics to participate, alongside tutors, in practical workshops to provide targeted content when and where it was needed by students. Previously, workshops had been led by tutors with little input from academics.

Enhancing student competence was a motivator for many of the educators to innovate their teaching; 'we were really trying to hit that middle range, which tend to drop off', 'I do feel [today's] students need a lot more shepherding, a lot more engaging ... [than] my generation needed'. Some educators adopted deliberate strategies to integrate content and pedagogy, in order to develop student competence:

Every week I have some kind of problem ... where I'm trying to achieve some kind of practice of [applying] the content that we've been discussing to a new problem, [with] a particular skill I'm trying to have them develop.

We wanted to make students aware of the scale of problems that are currently facing the planet and to educate them to the point they're able to make informed decisions about how best to tackle these problems.

The desire to enhance student competence was discussed in relation to academic success, students' use of digital tools, extra-curricular course-related projects (e.g. performing a play) and pedagogical approaches for their current learning (e.g. finding key messages from course literature) or future study (e.g. rationalising information from a range of sources). One participant talked of the need for innovative approaches to teaching in 
order to address the lack of gender and ethnic diversity in the student cohort for his discipline area. With reference to the 'white male' dominated teaching staff, he said,

There is no way that we can deliver content in an appropriate way for them [diverse students], because we don't have that knowledge or skillset.

Teaching innovations were also designed to empower students to develop their own competence:

[I found students wouldn't] actually let me know if they weren't following concepts or they didn't understand what I wanted them to do ... so I try to create situations where people feel comfortable to reveal their 'shameful lack of confidence'; to really ask for instructions.

The interrelated nature of educator and student competence was evident in many educator responses; 'we tried it - they loved it', 'I get more consistent results from the marking [as a result of the innovation]', and:

I think how they engage in assignments ... I've seen students become more innovative ... So

I try to kind of, model what I'm asking for as well.

Positive student feedback and improved engagement or achievement enhanced educators' feelings of competence lead to further uptake of innovative practices.

In addition to content competence, all participants expressed keen interest in and feelings of competence in relation to pedagogy. One identified skills in public speaking, describing them as his greatest asset in getting students to engage in lectures. Along with this, he undertook careful planning of lectures to 'chunk' the information and incorporate opportunities for students to review their understanding: evidence of informed pedagogical decision making. Another participant described dissatisfaction with didactic approaches to teaching, and a desire 'to try to enthuse the students by getting them involved in learning - by engaging them'.

This notion of a commitment to ongoing development of competence in terms of pedagogy was a common theme amongst participants:

For me it needs to be also fun and interesting ... If I'm not engaged, then I know my students won't be. So, I need to find ways that I remain engaged. So that's what motivates me to create new activities or new assignments, because I just get bored with ones that have been going too long.

I think about 'how do I get [an online] dynamic environment going where people are talking to one another?' ... I'm always looking to make it more immediately intuitive ... [students] are doing marvellous things on their [online environment]. We're all learning ... different ways of [using] it.

There was acknowledgement that not every pedagogical innovation worked or was successful with every group of students; 'You know a lot of it is just trial and error too. I've made a lot of mistakes ... trying new things that I thought would be wonderful and they just absolutely flopped'. But this did not deter these expert educators from continuing to innovate their teaching, which is testament to their sense of pedagogical competence. For one participant, a strong sense of pedagogical competence drove her ongoing learning about digital technologies, where she felt less competent, to achieve interaction with and amongst students in an online course. 
A lot of things I've got to find out for myself because there might be a real delay if I try getting hold of IT ... I YouTube or Google it, so I usually find out a way ... [because] we should all be moving along the lines of interactive [teaching online].

Pedagogical competence and confidence were defining characteristics of these expert educators. They had varying levels of experience and professional development in tertiary teaching, but all communicated a sense of self-awareness and self-efficacy in relation to their competence as teachers, coupled with a desire to continually improve their practice.

\section{The need for autonomy}

Closely related to competence was evidence that all the participants felt they had sufficient autonomy to make changes to their teaching approaches. Even when teaching only one part of a course, educators seemed to have the freedom (and/or determination) to initiate innovative practices, for example, through the assessment tasks they set. Many of the educators talked of continually adapting their teaching, informing their teaching through reading, adapting ideas from other disciplines, trying out new digital tools, and being free to create new teaching ideas and adopt pedagogies that worked well for their own teaching style.

Support from the institution via professional learning opportunities, grants to support teaching innovations, and dedicated educational design staff contributed to a sense of autonomy (and competence) for some participants; 'I feel like the environment's really conducive to trying new things'. Several participants were given an explicit mandate to undertake innovations: in particular, courses to address poor student evaluations or high attrition rates.

So I always had a really clear goal [set by the dean]. It was to increase the average grade, and increase the number of students that had gotten through.

Some participants reported that resourcing was provided to support such development.

They gave us some funding to work together on that first year.

I've got the support team that allows me to do it. I've got one and a half dedicated teaching staff to support me, including a technician ... So I've got a huge amount of support from the Head of School.

For others, a sense of autonomy was driven by self-belief and a strong sense of teaching efficacy, sometimes in the face of what were seen as unhelpful institutional systems and practices. For example, inter-disciplinary collaboration was prevented by administrative systems unable to cope with dual-coded courses - 'We had to choose which discipline got it, because double-labelled courses were too confusing to administrate'. There was also sense of having justify pedagogical approaches that were not seen as 'the norm' - 'if you want to do something like peer assessment you need special permission and oversight', and 'I've had to use statistics as a weapon to justify the efficacy of my teaching methodology'. For one participant, acknowledgement of the positive support provided by the institution for innovative approaches was tempered by a feeling that the institution had a 'set of requirements around innovation' that could compromise educators taking up innovative approaches simply for the 'joy of it'. 
Autonomy was also discussed in relation to building student autonomy, particularly around providing choice about content (e.g. 'There's an opportunity for students to go and research more about these "buzzword" topics if they're interested'.), access to learning materials (e.g. ensuring online students have access to campus tutorial discussions), assessment content ('[l say] research something that you are interested in, and just write about it, and then you'll incorporate it into a performance ...' The parameters of that are just so wide'.) and style of assessment format (e.g. open choice including digital, written, movie, etc.). Some reported making many opportunities for developing student autonomy:

I engage students by turning decision making power to them - as early and as often as possible ... trying to make them the centre of the decision making ... everything they do is authentic and high stakes...

Educators sought to enhance student autonomy through encouraging student decisionmaking, enabling students to work to their strengths and be themselves in class, and through nurturing their interests and creativity:

I'm really into [the] model of support to pass ... so finding ways of [supporting], like make up assessments, expanding and flexible submission, non-mandatory requirements ... but also, 'you're responsible for your own learning'.

Autonomy seemed to work as a motivator on several levels. At an individual level, a sense of autonomy encouraged and enabled educators to implement teaching innovations. At a pedagogical level, some innovations were designed so that students could be more autonomous, suggesting some educators, consciously or unconsciously, recognised the power of having autonomy for enhancing student engagement.

\section{The need for relatedness}

Attention to the need for relatedness was strongly evident in the data and motivated many participants to innovate in particular ways. For example, one educator talked of their teaching innovation being designed to 'allow students to gain a new perspective on the world and their lives, to develop citizenship and personal wellbeing and happiness'. Others also spoke directly or indirectly about enhancing student citizenship and wellbeing. Educators also talked of developing relatedness between students, between themselves and students, and between students and society, as motivations for and as results of innovation. Several talked of their desire to establish partnership-style relationships with students to nurture a sense of belonging in the course:

I get to know the students ... find out who they are ... So if I open up first ... this is me, this is my dogs and my family ... I think because they do feel valued and included, I think that rubs off on the degree to which they engage with the course.

When they see that I'm interested in who they are as people - that changes things quite a bit.

I want to respect them as individuals, but also as representing communities and families ...'

Educators used a range of strategies to promote relatedness. One educator made herself available out of classtime in a central meeting place in the university for 'coffee and craic'. Students could turn up and ask questions or discuss content, creating a sense of social 
connection amongst the student group as well as with the educator. The most common strategy was the use of small group interactive and collaborative activities:

It's very interactive and so the group - gradually you see them relaxing ... you want people to feel comfortable and feel 'I can do this'.

I think lecture spaces are quite intimidating ... so I tend to do stuff where they're talking in small groups.

Relatedness was discussed in relation to using practices consistent with culturally responsive teaching (Gay 2010) to meet diverse needs, and address social justice. For example, encouraging Indigenous Māori and Pacific Nations students to see their diversity as an asset, and prioritising culturally located concepts and practices, such as akō (reciprocity), kanohi ki te kanohi (face to face connections), responding in ways consistent with Māori cultural values:

The thing that I care about the most is the integrity of the material and steering away from Western-driven theory.

The interplay between relatedness and wellbeing was evident in educator responses. For example, beliefs that learning is a holistic rather than solely cognitive experience were apparent in educator descriptions of how they intended their innovations to develop student competence:

I think asking people something personal and asking them to contribute is what gets them thinking and hitting you in the heart, because I think learning is very much emotional, as well as intellectual.

\section{Wellbeing as an outcome}

Deci and Ryan $(2017,86)$ discuss that when any of the three basic needs is 'frustrated or neglected ... the individual will show ... lowered vitality, loss of volition, greater fragmentation, and diminished wellbeing'. Our participants made connections to their own wellbeing and how they felt innovating their teaching was important to their sense of enjoyment ('I can't just talk at people for 45 minutes because I wouldn't enjoy that') and interest in their work ('I'm always interested in finding new ways - like technology').

Our findings suggest that a complex interplay of aspects of educators' wellbeing and their perceptions of their students' wellbeing can exist when educators strive to teach in innovative ways. For example, being personally engaged in one's teaching was linked to students being more likely to be engaged:

If I'm not engaged then I know my students won't be, so I need to find ways that I remain engaged. So that's what motivates me to create new activities or new assignments, because I just get bored with ones that have been going for too long, and that sort of helps me to lift my energy as well; having new things, and again things that I think are engaging.

Participants talked of feeling uncomfortable when changing their practice and the potential effect of this discomfort on evaluating the effectiveness of the innovation for learners:

The hardest thing about being an innovative educator is the fact that what you are doing right now is really comfortable and doing anything other than what feels comfortable is going to be uncomfortable. The feeling of discomfort will prevent you from being able to judge accurately whether what you are doing is actually working. 
The complex impacts of wellbeing included that, while educators discussed feeling uplifted and inspired by planning to teach and teaching in novel ways, at times this work also placed unsustainable demands on their time and energy. Participants described that the time and energy needed to 'develop', 'try', 'adapt', and 'refine' 'new tools' and 'strategies', to 'plan diversity of tasks' and 'to share with colleagues' may not be sustainable without support:

I haven't done [this type of innovation] again, but that's because in hindsight I know the amount of work, the amount of time, the amount of effort.

I think I could be more innovative if I had time, and the university allowed me time to think about it.

While participants acknowledged the commitment and support provided by the university for some aspects of innovative teaching, there was also frustration in relation to some wider university systems and processes that they felt undermined more substantial innovations being incorporated into coursework and assessment. Specific concerns related to necessary compliance with administrative systems and requirements, introducing practice-oriented learning and assessment in a theory- and research-led institution, perceptions of the institution's lack of flexibility and ability to compromise, inadequacy of digital technology resources in relation to pedagogical usefulness and student access, and lack of follow up to support implementation of policy:

So, the university has this wonderful digital teaching and learning strategies and vision and everything, but we're not seeing the support coming down with that ... we're expected to do it alongside everything that we already do. They're quick to buy the technology, but to really invest in people and time is another story.

In spite of the positive impact of pedagogical innovations on their sense of wellbeing, some participants stated that innovating in their teaching also had a personal cost. For example, the costs included a sense that their chances of promotion were compromised and also risks of negative colleague perceptions. While these factors may have impacted the kinds of innovations that some educators were able to implement, enhanced student wellbeing and learning were a key motivation for the educators to continue their efforts. Such student responses included increased enjoyment and engagement in course work, improved assignment work, greater creativity, better attendance, retention and achievement:

We've got some evidence that students on the whole really enjoyed being able to connect with place.

We had much better attendance ... [we] kept them there and kept them engaged.

I've seen students become more innovative in that space.

Such comments indicate enhanced feelings of educator competence, again linked closely to educator wellbeing.

\section{Further discussion}

Our study illuminates the need for tertiary institutions to understand educators' motivations to innovate their teaching in order to appropriately support them to develop their teaching, and, through this, maximise student engagement, learning and achievement. Using an 
underpinning framework based on notions from SDT our analysis of the participant interviews suggests how human needs for competence, autonomy, relatedness, together with connections to wellbeing as an outcome, can inform understanding about why educators may or may not initiate and maintain innovative teaching practices. Further, we believe that SDT could be a useful tool to help inform institutional decision-making about the design of systems and programmes supportive of innovative teaching, and individual educators' development, implementation and evaluation of teaching innovations. For example, the need for educators to be strongly committed to innovating in tertiary teaching in order to embed new practices can be understood by considering the demands of innovative practice on competence, autonomy and relatedness. Despite potentially positive student feedback and enhanced student achievement, negative feedback from colleagues about one's work can reduce a sense of competence. Navigating university processes and systems can reduce one's sense of autonomy, and perceiving a reduced chance of promotion or that the university community does not value teaching innovation can reduce one's sense of relatedness with that community. Such effects can help explain why the innovative educators in our study often focussed their innovation efforts on one or only a small number of courses.

Our findings imply that effort and commitment are needed to maintain motivation to innovate in tertiary teaching. Changing practice to include innovation is demanding in time and effort, both for creating and embedding innovations in practice. However, working with others and reflecting team priorities can support enhancement all three psychological needs and, hence, can contribute to innovative practices. In general, educators' student-focussed motivations identified in this study were to enhance student engagement, achievement, and the transfer of useful content and non-content related skills, knowledge, and behaviours to further learning and employment. Personally-focussed motivations included following content and pedagogical passions, wanting to continually develop and improve practice, and maintaining interest in material that had been taught many times. None of the educators stated that they were motivated by university incentives to be innovative, by following others' innovative practices, or by the idea of being innovative (one going so far as to state 'my intention wasn't to be innovative'). However, many attributed their innovations to ideas picked up from colleagues, or from engagement with tertiary teaching qualifications, and interactions with staff in the university's Centre for Academic Development. These findings suggest an important role for professional learning in supporting pedagogical competence for innovating practice.

The study provides further evidence that the term 'innovative pedagogy' is a challenging one to interpret. While our interviews focussed on teaching elements that the participants believed to be the most innovative in their practice, most participants questioned what was meant by the term 'innovative' and whether or not their own teaching strategies represented innovative practice. Many noted the contextualised nature of innovation, suggesting that what was considered innovative in one context might not be seen as such in another.

\section{Limitations}

It is important also to note that the different approaches to data gathering (i.e. individual and paired interviews) may have influenced the content and nature of participant responses. It is also acknowledged that the study was small in scope. However, our intention is not to generalise; rather it is to provide insights based on an in-depth, qualitative analysis. 


\section{Conclusion}

This small scale study resonates with previous studies (e.g. Hannan, English, and Silver 1999), as our findings indicated that expert educators share similar motivations for innovating in their teaching (e.g. enhancing student learning and engagement, retaining their own enthusiasm in their teaching), and similar affordances to innovative practice (e.g. suitable professional development) and constraints (e.g. time needed, perceptions of lack of institutional benefit relating to their work). These findings imply that without a suitable institutional environment that fosters competence, autonomy, and relatedness, teacher development or incentivised innovation programmes alone are unlikely to bring about broad and deep pedagogical change. Further work is clearly needed to explore the interconnected nature of educator and student feelings of competence, autonomy and relatedness in relation to teaching in higher education. Given the increasing levels of stress and financial commitment being experienced by students in many tertiary education contexts, there is an ever increasing need to document ways to enhance the wellbeing of individuals, cohorts, and communities within higher education. Studies which incorporate student voice would be helpful to understand student perspectives of their psychological needs whilst under the academic and financial pressures of high stakes study. Our work indicates that Ryan and Deci's (2000) SDT may provide a useful tool in this endeavour.

\section{Acknowledgments}

We would like to acknowledge the contributions of the following people from the research team to this work: Liz Jones, Bernadette Knewstubb, Sandi McCutcheon, Anita Mortlock and Amanda Gilbert.

\section{Disclosure statement}

No financial interest or benefit that has arisen from the direct applications of this research.

\section{Funding}

This project was supported by strategic funding from the Faculty of Education at Victoria University of Wellington, Te Herenga Waka; Faculty of Education, Victoria University of Wellington [Grant number 217721].

\section{ORCID}

Robin Margaret Averill (D) http://orcid.org/0000-0002-8941-5565

Jae Major (D) http://orcid.org/0000-0003-1302-4768

\section{References}

Adams Becker, S., M. Cummins, A. Davis, A. Freeman, C. Hall Giesinger, and V. Ananthanarayanan. 2017. NMC Horizon Report: 2017 Higher Education Edition. Austin, TX: New Media Consortium.

Aldrup, K., U. Klusmann, and O. Ludtke. 2017. "Does basic need satisfaction mediate the link between stress exposure and wellbeing? A diary study among beginning teachers." Learning and Instruction 50: 21-30. doi:10.1016/j.learninstruc.2016.11.005. 
Backhouse, J. 2013. "What makes lecturers in higher education use emerging technologies in their teaching?" Knowledge Management and E-Learning 5 (3): 345-358.

De Charmes, R. 1968. Personal causation. New York: Academic Press.

Deci, E. L., and R. M. Ryan. 2008. "Self-determination theory: A macrotheory of human motivation, development, and health." Canadian Psychology/Psychologie Canadienne 49 (3): 182-185. doi:10.1037/a0012801.

Deci, E. L., and R. M. Ryan. 2017. Self-determination theory. Basic psychological needs in motivation, development and wellness. New York: Guilford Press.

Furco, A., and B. E. Moely. 2012. "Using learning communities to build faculty support for pedagogical innovation: A multi-campus study." The Journal of Higher Education 83 (1): 128-153. doi:10.1080/00221546.2012.11777237.

Gan Joo Seng, M., and J. Geertsema. 2018. "Sharing practices, but what is the story? Exploring award-winning educators' conceptions of teaching." Higher Education Research and Development 37 (2): 254-269. doi:10.1080/07294360.2017.1373331.

Gay, G. 2010. Culturally responsive teaching: Theory, research and practice. 2nd ed. New York: Teachers College Press.

Hannan, A., S. English, and H. Silver. 1999. "Why innovate? Some preliminary findings from a research project on 'Innovations in teaching and learning in higher education'." Studies in Higher Education 24 (3): 279-289. doi:10.1080/03075079912331379895.

Henard, F., and D. Roseveare. 2012. "Fostering quality teaching in higher education: Policies and practices. An IMHE Guide for higher education." http://www.oecd.org/education/imhe/QT\%20poli cies\%20and\%20practices.pdf

Hobson, A. J., and B. Maxwell. 2017. "Supporting and inhibiting the wellbeing of early career secondary school teachers: Extending self-determination theory." British Educational Research Journal 43 (1): 168-191. doi:10.1002/berj.3261.

Kennedy, G., B. Dalgarno, S. Bennett, K. Gray, T. Judd, J. Waycott, R. Chang, A. Bishop, K. Maton, and K.-L. Krause. 2009. "Educating the Net Generation: Implications for learning and teaching in Australian universities." Final report. Sydney: Australian Learning and Teaching Council.

Kettunen, J., L. Kairisto-Mertanen, and T. Penttilä. 2013. "Innovation pedagogy and desired learning outcomes in higher education." On the Horizon 21 (4): 333-342. doi:10.1108/OTH-08-2011-0024.

Law, N. 2014. "Comparing pedagogical innovations." In Comparative Education Research: Approaches and Methods, edited by M. Bray, B. Adamson, and M. Mason, 333-364. 2nd ed. Switzerland: Springer International.

Layne, P. C., and P. Lake, eds. 2014. Global innovations of teaching and learning in higher education: Transgressing boundaries. London: Springer.

Lock, J., B. Kim, K. Koh, and G. Wilcox. 2018. "Navigating the Tensions of Innovative Assessment and Pedagogy in Higher Education." The Canadian Journal for the Scholarship of Teaching and Learning 9 (1). doi:10.5206/cjsotl-rcacea.2018.1.8.

Martín, P., K. Potočnik, and A. B. Fras. 2017. "Determinants of students' innovation in higher education." Studies in Higher Education 42 (7): 1229-1243. doi:10.1080/03075079.2015.1087993.

McCurry, M. K., and D. C. Martins. 2010. "Teaching undergraduate nursing research: A comparison of traditional and innovative approaches for success with millennial learners." Journal of Nursing Education 49 (5): 276-279. doi:10.3928/0148834-20091217-02.

McLoughlin, C., and M. J. W. Lee. 2010. "Personalised and self-regulated learning in the Web 2.0 era: International exemplars of innovative pedagogy using social software." Australasian Journal of Educational Technology 26 (1): 28-43. doi:10.14742/ajet.1100.

Merriam, S. B. 2002. Qualitative research in practice: Examples for discussion and analysis. San Francisco: Jossey-Bass Inc Pub.

Porter, W. W., and C. R. Graham. 2016. "Institutional drivers and barriers to faculty adoption of blended learning in higher education." British Journal of Educational Technology 47 (4): 748-762. doi:10.1111/bjet.12269.

Ryan, R. M., and E. L. Deci. 2000. "Self-determination theory and the facilitation of intrinsic motivation, social development, and wellbeing." American Psychologist 55 (1): 68-78. doi:10.1037/0003066X.55.1.68. 
Schell, K. A. 2006. "A Delphi study of innovative teaching in baccalaureate nursing education." Journal of Nursing Education 45 (11): 439-448. doi:10.3928/01484834-20061101-03.

Seely Brown, J., and R. P. Adler. 2008. "Open education, the long tail, and learning 2.0." Educause review 43 (1): 16-20.

Smith, K. 2011. "Cultivating innovative learning and teaching cultures: A question of garden design." Teaching in Higher Education 16 (4): 427-438. doi:10.1080/13562517.2011.560374.

Stupans, I., S. Scutter, and K. Pearce. 2010. "Facilitating student learning: Engagement in novel learning opportunities." Innovative Higher Education 35 (55): 359-366. doi:10.1007/s10755-0109148-6.

Walder, A. M. 2014. "The concept of pedagogical innovation in higher education." Education Journal 3 (3): 195-202. 